\title{
Bilateral ovarian carcinoma with bilateral uveal melanoma
}

\author{
JOAN MUllaney,' D. MOONEY,' M. O'CONNOR,' AND G. S. A. McDOnALD² \\ From the 'Royal Victoria Eye and Ear Hospital, and ${ }^{2}$ St James's Hospital, Dublin
}

SUmmary A case of bilateral uveal melanoma in a 60-year-old woman in association with primary bilateral ovarian carcinoma is described. This is the first case in which ultrastructural studies have been performed on the ocular tumours. Seven previously described cases are summarised, and the extreme rarity of such reports would suggest that this may indeed be a new syndrome.

The coincidence of diffuse bilateral uveal melanocytic infiltrations with a dissociated visceral malignancy has only recently begun to be reported. ${ }^{1-4}$ Barr et al. ${ }^{1}$ collated 4 cases which were available to the Armed Forces Institute of Pathology in Washington and added 2 of their own, believing that this unusual occurrence represented a new syndrome. Table 1 summarises the reports to date. It is the purpose of the present paper to contribute an eighth such case.

Correspondence to Dr Joan Mullancy. National Ophthalmic Pathology Laboratory. Royal Victoria Eve and Ear Ilospital. Dublin 2. Ircland.

Table 1 Summary of cases reported to date

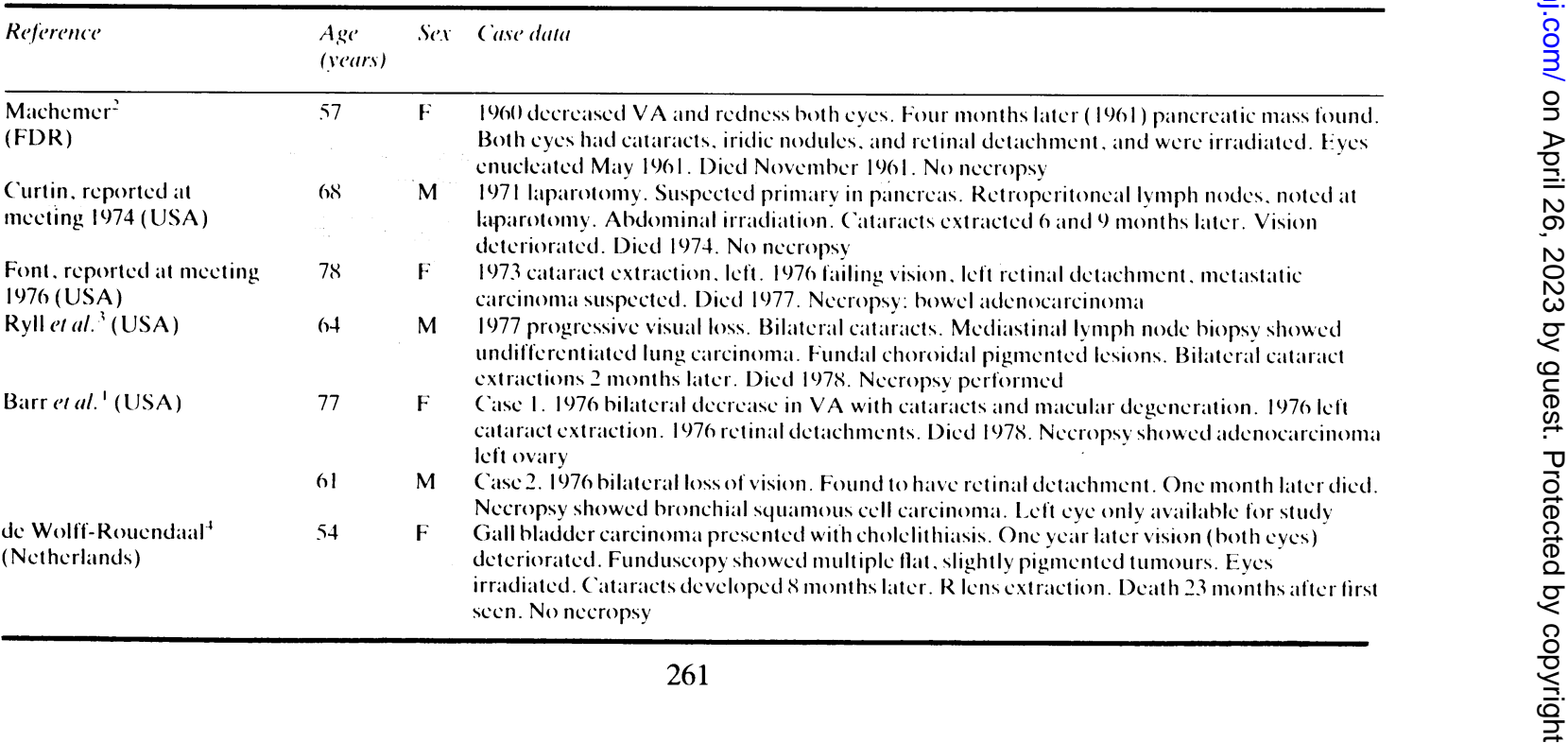


Fig. 1 Ovarian carcinoma with focal calcification (arrow). (Haematoxylin and eosin, $\times 4.3$ ).

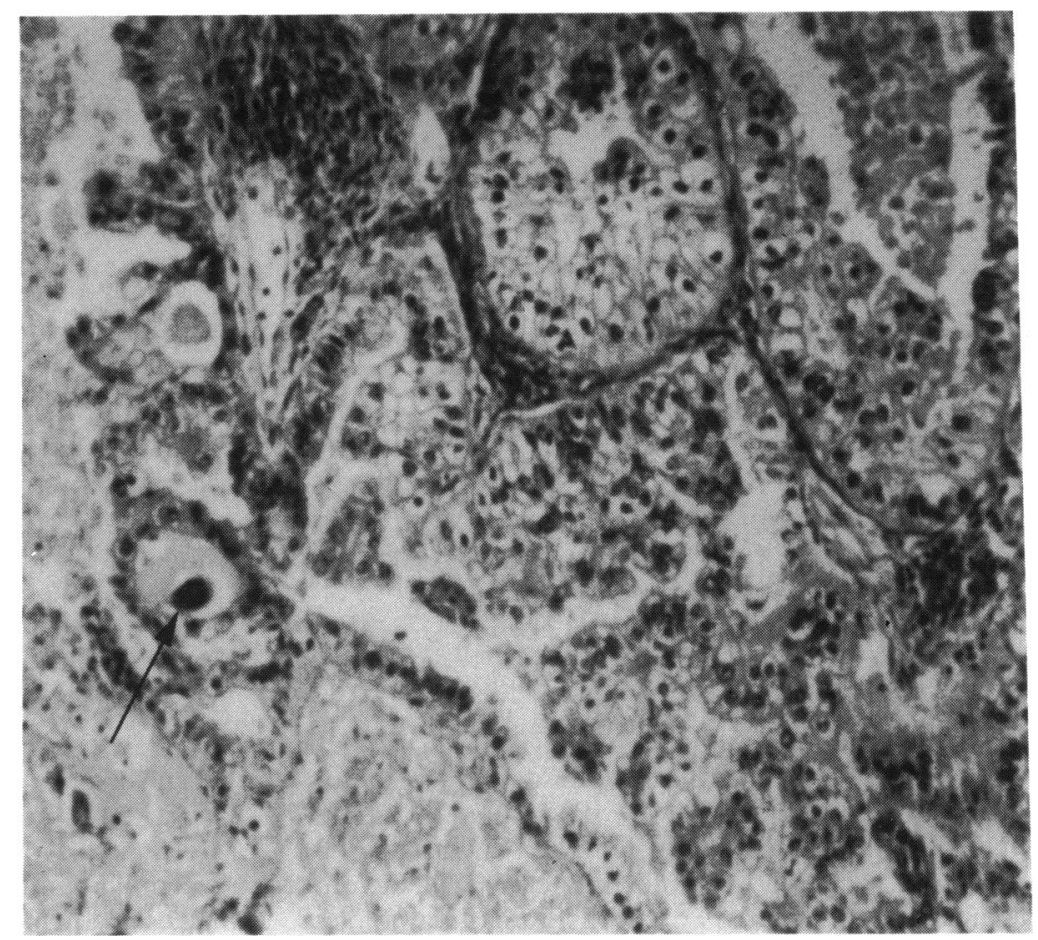

spironolactone. Family and social histories were unremarkable.

On examination the visual acuity was $6 / 24 \mathrm{RE}$ and 6/36 LE. The right cornea and iris were normal, but there were numerous small round scars in the subepithelial region of the left cornea suggestive of a previous viral keratitis. There was an area of about 2 $\mathrm{mm}$ in diameter of thickening of the left iris stroma, with a few overlying vessels at the 5 o'clock position. The lenses were clear, but bilateral phakodonesis was present. Intraocular pressures were normal, 17 $\mathrm{mmHg}$ in the right eye and $15 \mathrm{mmHg}$ in the left eye (applanation). The right vitreous was clear and the right disc and blood vessels were normal, but the macula appeared to be slightly elevated due to either oedema or a subretinal mass, and there was what appeared to be a small choroidal naevus in the upper nasal quadrant of the right fundus measuring about 3 $\mathrm{mm}$ in diameter. The left vitreous, disc, and blood vessels were also normal, but the left macula had a thickened oedematous appearance similar to that of the right macula. There were 2 pigmented slightly raised lesions measuring about $4-6 \mathrm{~mm}$ in diameter, one in the lower nasal periphery and one in the upper temporal equatorial region of the left fundus. The lower one-third of the left retina was detached, but no retinal tear was seen.

The patient was seen again on 28 April 1982, and the only significant change was a subtotal retinal detachment in the left eye with a drop in visual acuity to hand movements. Chest $x$-ray and brain scan were normal, but bone scan suggested metastatic disease involving the bones of the spine. Left ocular ultra-

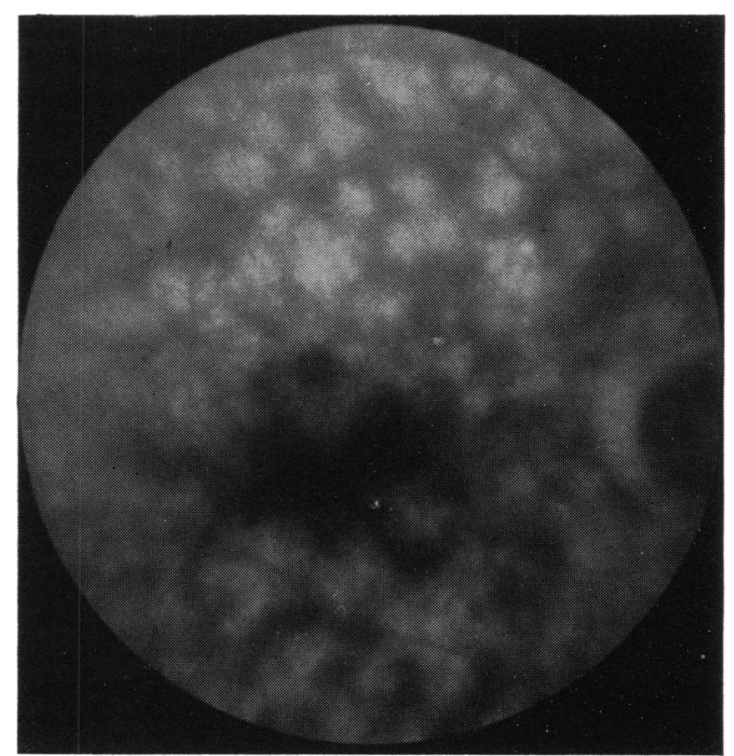

Fig. 2 Fluorescein angiography: widespread, blotchy dye leakage from the choriocapillaris and around the posterior pole in both fundi (righ fundus shown above). 
sound confirmed the presence of retinal detachment but did not reveal any choroidal masses. The left electroretinogram was extinguished. Fluorescein angiography (Fig. 2) revealed a widespread blotchy pattern of dye leakage throughout both fundi, in particular around the posterior poles of both eyes. The appearance was suggestive of a generalised choroidal inflammation. The patient was admitted to hospital on 16 June 1982, when vision had dropped to

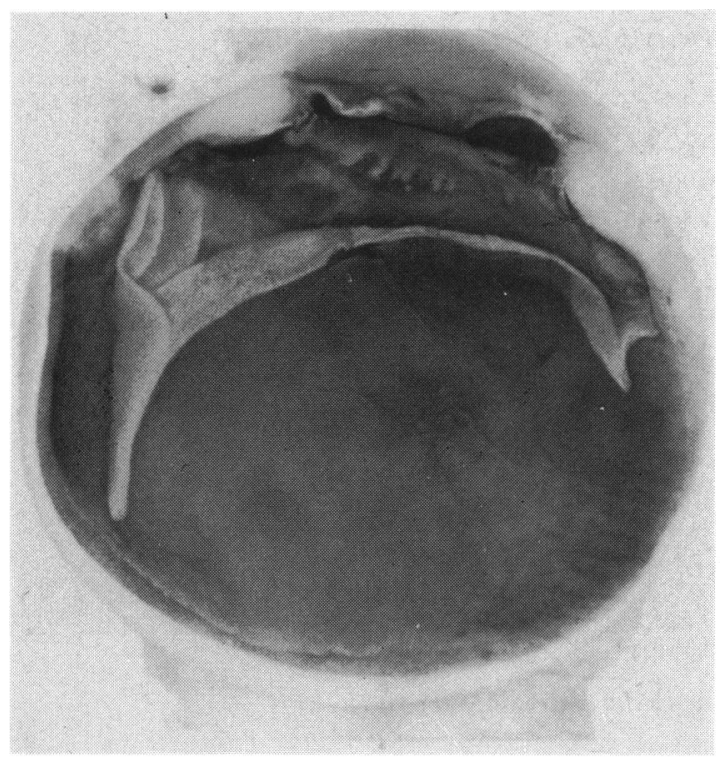

Fig. 3A

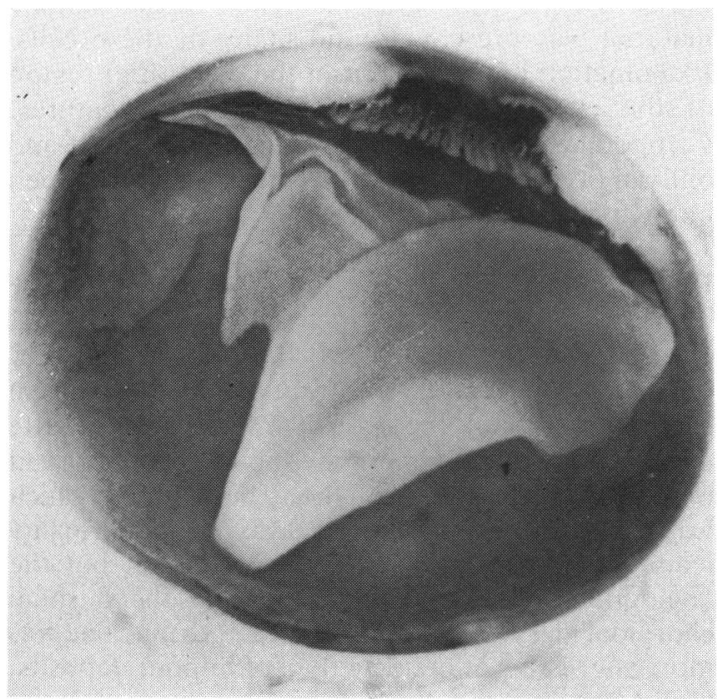

Fig. 3B

Fig. 3 Calottes of (A) right and (B) left eye with panueveal thickening and retinal detachments. hand movements in the right eye and no perception of light in the left eye, due to lower-half retinal detachment in the right eye and total detachment of the left retina. There were now dense lens opacities in both eyes, and ultrasonography showed the presence of a lower-half retinal detachment in the right eye and a total detachment in the left eye. A course of oral prednisolone $120 \mathrm{mg}$ daily was started on 22 June 1983 without any improvement in the clinical condition. All blood investigations were normal, and general physical examination was unremarkable apart from an abdominal scar.

The cataracts rapidly matured, and bilateral lens extractions with sector iridectomies were carried out on 1 July 1982. Bilateral hyphaemata were noted at first dressing. Within 24 hours the patient developed severe abdominal pain, and she died the following day. No permission was granted for necropsy, but the eyes were removed for pathological examination.

\section{OCULAR PATHOLOGY}

Macroscopic examination (Fig. 2) of both eyes, which measured $24.5 \times 24 \times 23 \mathrm{~mm}$, showed extensive retinal detachment and solid masses about $3 \mathrm{~mm}$ thick at the ciliary body, spreading to fill the choroid as far as the optic disc (Figs. 3A, B). In the left eye an elevated (3 $\mathrm{mm}$ ) black tumour lay in the choroid behind the nasal equator.

Microscopic examination showed mild autolytic changes in the cornea, with occasional infiltration by polymorphonuclear leucocytes. There was a linear limbal scar, with neighbouring sutures without a cellular reaction. Haemorrhage was confined to the anterior chamber, and there was surgical aphakia. Much of the iris was filled by neoplastic tissue at different levels, and this process continued to cause widespread panuveal thickening to the optic disc (Figs. 4A, B). The cells were mixed polyhedral and spindle (Figs. 5A, B). Melanin pigment was irregularly and coarsely dispersed with fine intracytoplasmic pigment granules. The architecture varied with occasional fasciculi and in some areas an alveolar pattern, the cells either lining these arrangements or lying free in the lumen. There was some variation in nuclear size and chromatin arrangement. A search of approximately 200 sections showed rare mitotic activity of abnormal form. Three small heavily pigmented foci lay in the outer choroidal layers of the nasal ciliary body and peripapillary regions. A bleach preparation showed fairly uniform spindle and polyhedral cells. The large melanin nodule in the nasal posterior uvea consisted of polyhedral and spindle cells of varying size and nuclear content. There was extension along the posterior ciliary nerve into the sclera by the lesion at some levels. Drusen with focal calcification, hyperplasia of retinal pigment epithelial 


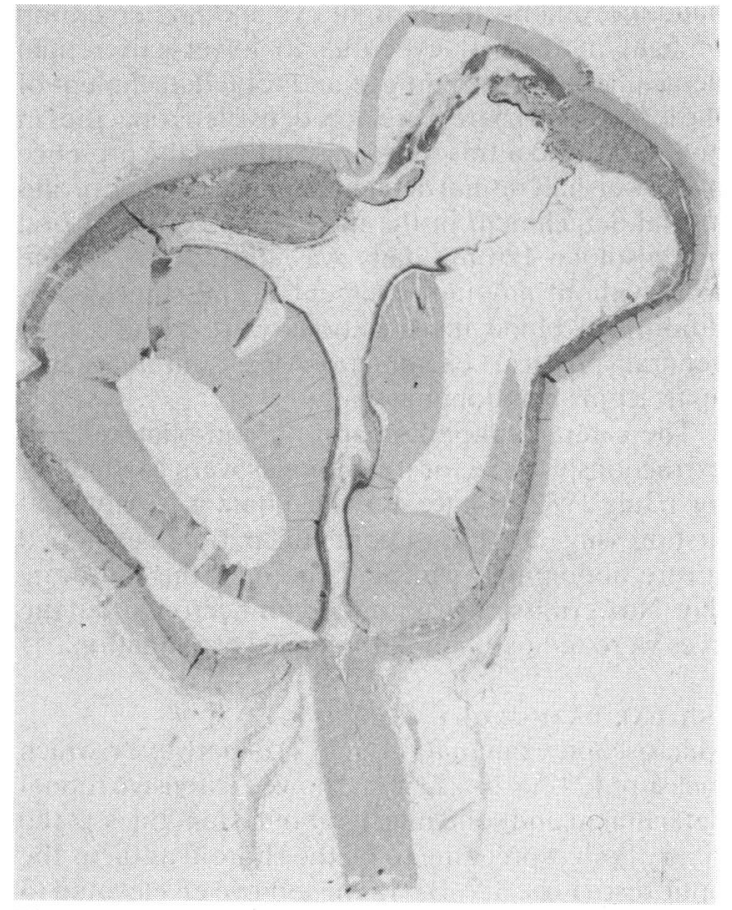

Fig. 4A

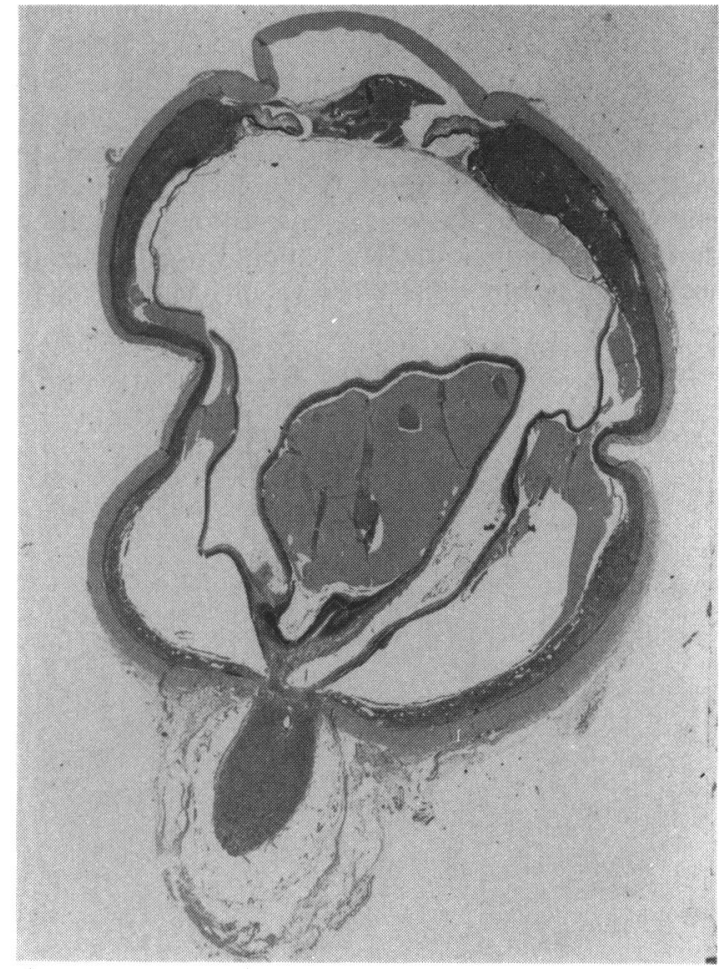

Fig. 4B

Fig. + Lefi (A) and righ (B) e'yes with panurecal tumours. (Hacmatorylin and eosin, $\times(0.65)$.

cells, and lipofuscin accumulations were widespread. The choriocapillaris was only focally obliterated by the neoplastic tissue. There were schisis and microcystoid changes in the periphery of the retina and extensive general retinal detachment with subretinal fluid accumulation and haemosiderin-laden macrophages. The optic nerve was not remarkable.

\section{EI.ECTRON MICROSCOPY}

The tissue was fixed in gluteraldehyde, postfixed in osmium tetroxide, stained with uranyl acetate/lead citrate, and examined in a Jeol $1000 \mathrm{CX}$ electron microscope.

The cytoplasm of the tumour cells (located behind the ciliary body) contained numerous compound melanosomes. Solitary melanosomes were found in a small group of cells only after a prolonged search. These were well developed, ellipsoid in shape, and showed characteristic cross-banded internal structure (Fig. 6). The nuclei of the cells were irregular with some infoldings. Nucleoli were not prominent. In some areas of close apposition of tumour cells desmosome-like structures were present, but no true desmosomes were seen. In many areas the tumour cells were separated from each other by collagen.
Other cells present showed the features of myofibroblasts with cytoplasmic filaments. Basal lamina material was present around many of these cells. Examination of sections from the equatorial region of the choroidal mass showed similar features. Compound melanosomes were more scattered and only an occasional ellipsoidal melanosome was seen but without cross-banded internal structure.

\section{Discussion}

The clinical appearance of the fundi was very suggestive of secondary deposits from the ovarian carcinoma, though the choroidal lesions were quite dark. Fluorescein angiography showed a widespread blotchy dye leakage throughout both fundi, which was suggestive of some choroidal vascular abnormality leading to leakage from choroidal vessels, but the angiogram did not help in outlining the 3 small choroidal masses. The elevation of both maculae was more suggestive of oedema than of tumour deposits. Ophthalmologically the patient's condition deteriorated rapidly, and her lenses, which had been noted to be clear but tremulous on 10 March 1982 had progressed to a state of mature cataract bilaterally by 


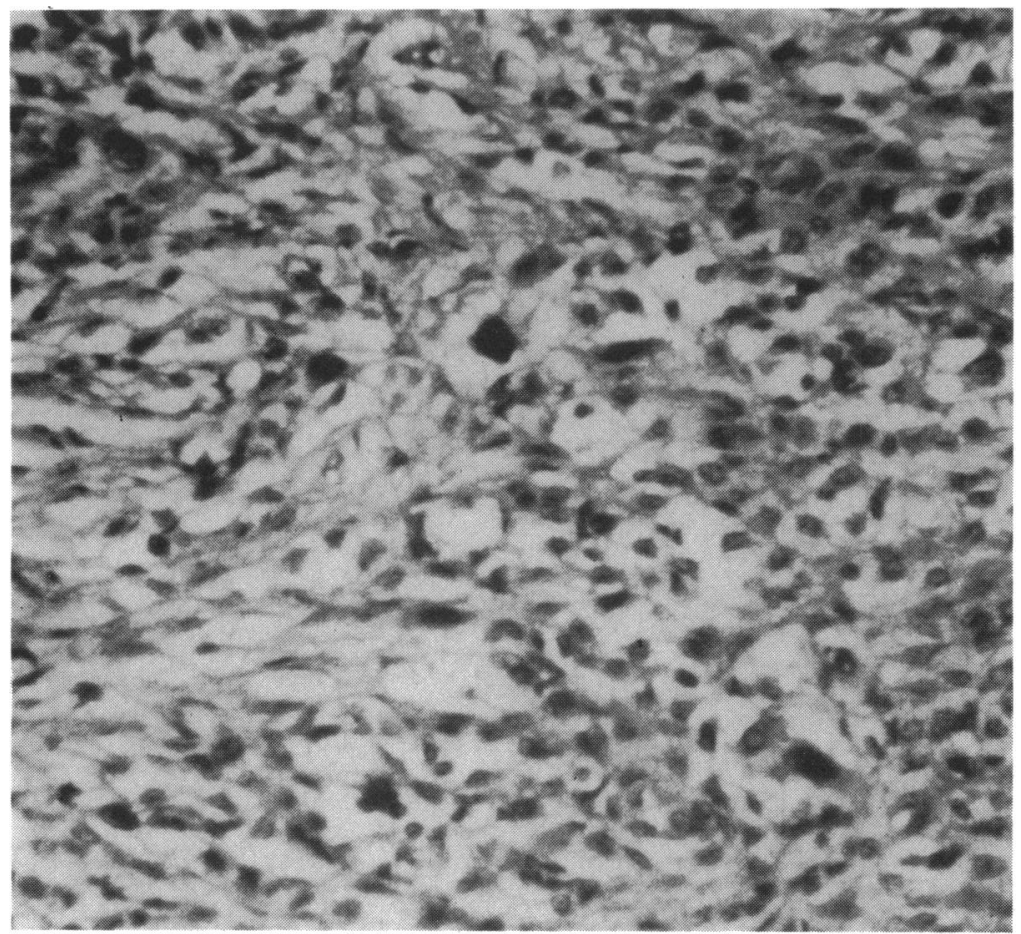

Fig. 5A Choroidal tumour pattern (right eye). (Haematoxylin and eosin, $\times 80)$.

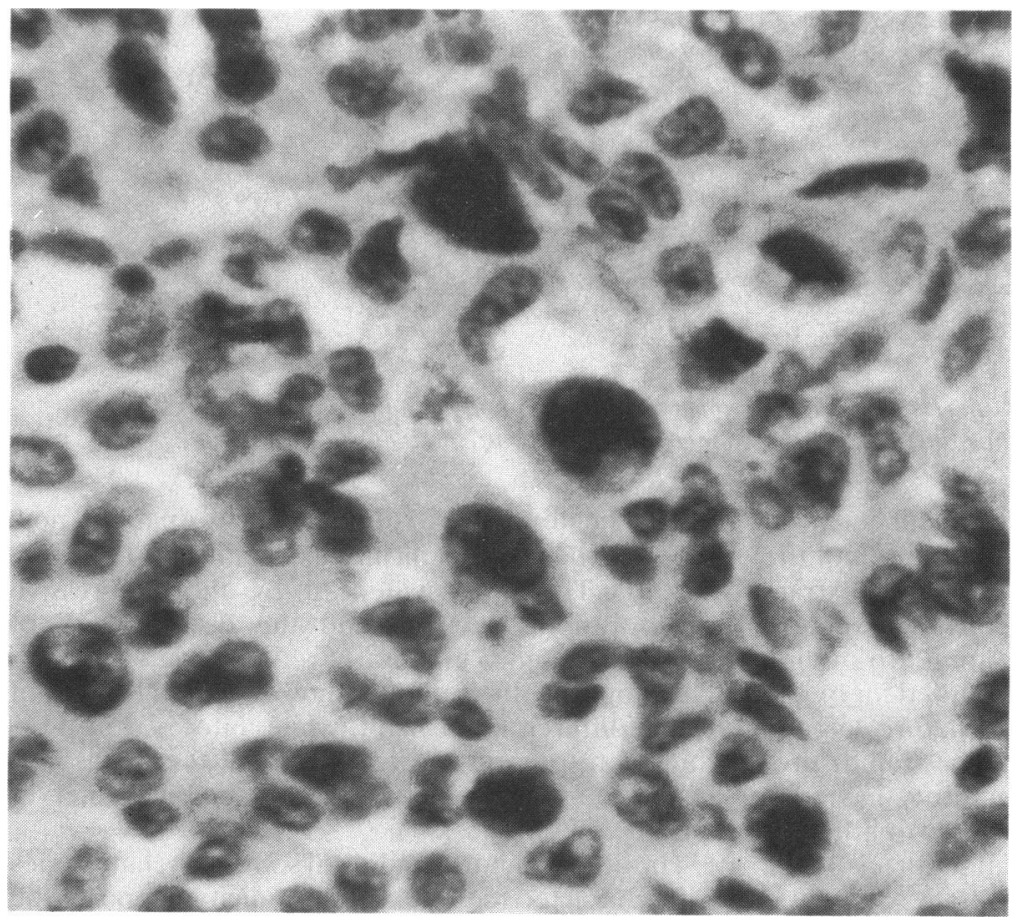

Fig. 5B Atypicalmelanomacells (choroid left eve). (Hacmatoxylin and eosin, $\times 200)$. 


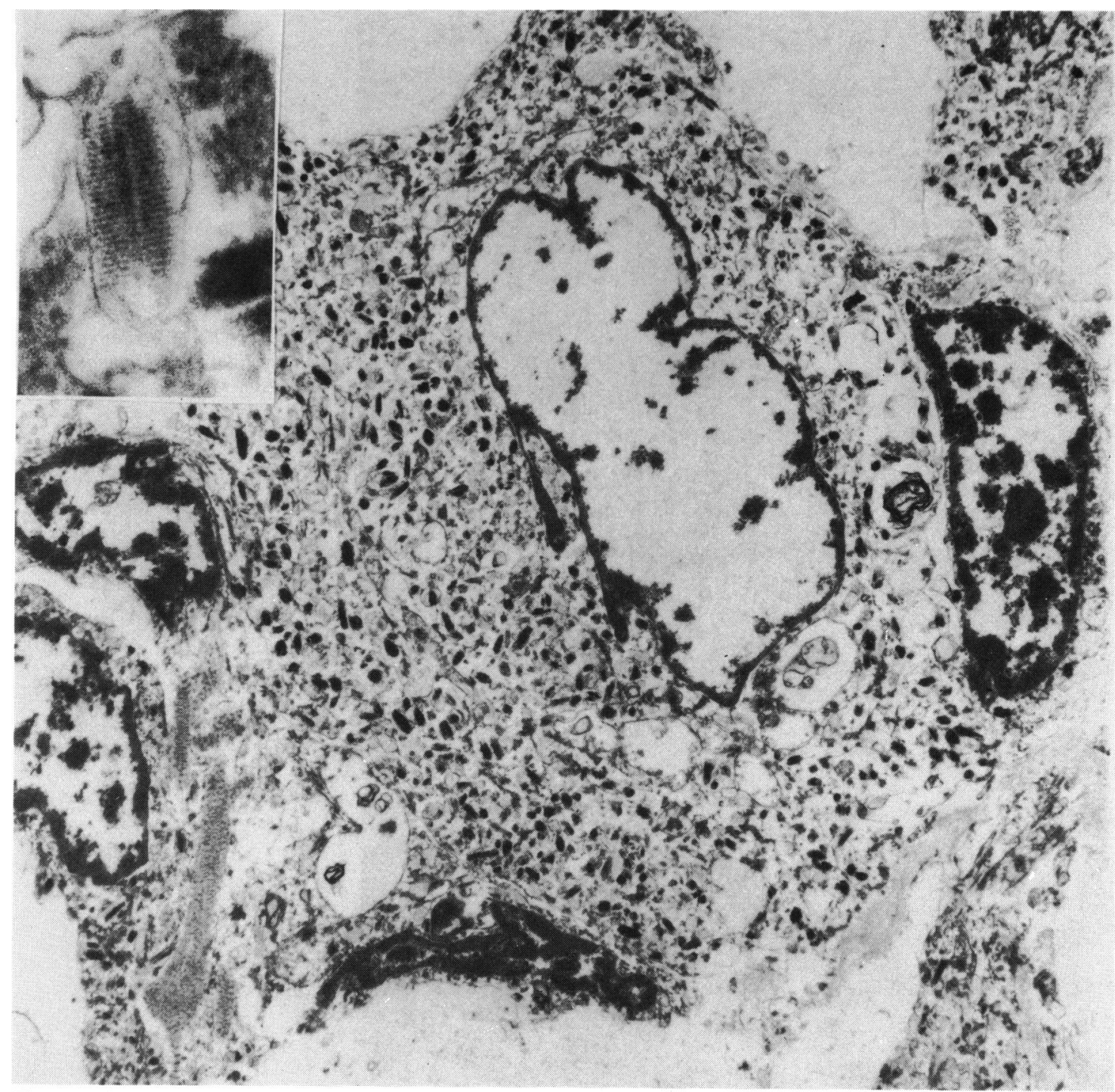

Fig. o Electron micrograph of a melanoma cefl showing electron dense melanin pigment, numerous compound melanosomes, and occasional melanosome (inset) with cross-banded internal structure. $(\times 990)$; inset $\times 64000)$ ).

the end of June 1982. As retinal detachment had been observed in both eyes prior to the maturation of the cataracts, it was decided to perform cataract extraction with a view to possible retinal detachment surgery at a later date. The failure of ultrasound to outline any choroidal tumours might be accounted for by the diffuse rather than the elevated nature of the choroidal masses histologically. The rapid progression of the lens opacities to maturity has been noted by other authors, and this rendered ophthalmic examination very difficult in the later stages of the disease.
The bilateral uveal tumours in the patient now reported behaved clinically as rapidly proliferating lesions. This was evidenced by the progressive deterioration in vision and the development of cataracts and bilateral retinal detachments. Histologically the tumours showed varying stages of cell dedifferentiation, and, while mitoses were few, they were present but atypical, and there was also evidence of early extension along the ciliary nerves into the sclera.

The ultrastructural finding of solitary melanosomes with characteristic internal periodicity supports the 
melanocytic nature of the tumour cells. Previously the histogenesis has been based on light microscopic appearances. This is the first case studied by electron microscopy. Although solitary (as opposed to compound) melanosomes have been described in a number of other tumours, including Schwannomas, ${ }^{5}$ the light and electron microscopic appearances in the present case indicate a melanocytic origin.

The cells were well differentiated and the melanosomes were relatively normal. While some workers have claimed that this supports the view that it is a benign naevus or at most a lentigo maligna in the skin, ${ }^{6}$ others have shown that this is not a reliable criterion. $^{7}$ Electron microscopy confirms the true melanocytic origin of these tumours but does not assist in determining their behaviour.

Machemer ${ }^{2}$ suggested that the diffuse uveal masses which he described represented proliferation of the Schwann cell system like that seen in the phakomatoses. Bilateral uveal malignant melanoma is extremely rare, with only 18 reports in the literature, ${ }^{\prime}$ and unilateral diffuse malignant melanoma is also uncommon, being found only in $5 \%$ of uveal melanomas. $^{80}$

It has been suggested ${ }^{1}$ that these cases are an oncogenic response to the same stimulus that caused the lethal carcinomas, but these writers state: it is our impression that these tumours essentially are benign and unlikely to metastasise, despite the presence of scleral extension in each case and malignant-looking epithelioid cells in 4 of their cases, and they draw a parallel between hamartomatous lesions and neoplasia such as is seen in Cowden's disease.

The role of radiotherapy with possible immunosuppression in the total of 8 cases reported to date cannot be evaluated. Three patients had no irradiation-Barr et al.'s cases 1, 2, and 4. 'There was abdominal radiotherapy in 2 patients (case 3 of Barr et al. ${ }^{1}$ and in the present case), and irradiation to the eyes was given in 3 patients, those of Barr and associates' case $3,{ }^{\prime}$ de Wolff Rouendaal, ${ }^{4}$ and Machemer. $^{2}$

We believe that the ocular tumours which we describe in our patient are malignant melanomata and that they appeared in association with visceral carcinoma. The explanation for this concurrence remains undetermined

We wish to acknowledge help from the following: Dr James O'Driscoll, Limerick, pathologist: Dr G. O'Reilly, Dublin, who referred the case to us; and Mr S. Travers, Mr R. Lester, Mr J. Dunne, and Miss C. Tyner for photographic, technical and secretarial assistance.

\section{References}

1 Barr CC, Zimmerman LE, Curtin VT. Font RL. Bilatcral diffuse melanocytic uveal tumours associated with systemic malignant ncoplasms. Arch Ophuhalmol 1982: 100: 249-55

2 Machemer R. Zur Pathogenese des flachenhaften malignen mclanoms. Klin Monatsbl Augenheilkd 1966: 148: 641-52.

3 Ryll DL, Campbell RJ, Robertson DM, Brubaker SJ. Pscudometastatic lesions of the choroid. Ophuhalmology 1980); 87: $1181-6$.

4 de Wolff-Rouendaal D. Bilateral diffuse benign melanocytic tumour of the uveal tract. A clinical pathological calse history. Ned Tijdschr Geneeskd 1983: 16: 7013.

5 Henderson DW. Papadimitriou JM. Ultrastructural appearances of tumours. 1st ed. London and Edinburgh: Churchill Livingstone. 1982.

6 Cesarini JP. Recent advances in the ultrastructure of malignant melanoma. Rev Eur Etudes (lin Biol 1971: 16: 316-22.

7 Mintzis MM. Silvers DN. Ultrastructural study of superficial spreading melanoma and benign simulants. Cancer 1978: 42: $5(1)-11$

8 Font RL. Spaulding AG. Zimmerman LE. Diffuse malignant melanoma of the uveal tract: a clinicopathologic report of 54 cases. Trans Am Acad (Ophthalmol Otolaryngol 1968; 72: 877-95.

9) Ferry AP. Font RL. (arcinoma metastatic to cye and orbit. Part 1. Clinicopathologic study of 227 cases. Arch Ophthalmol 1974: 92: $276-86$. 